\title{
ANALISIS BREAK EVENT POINT (BEP) SEBAGAI ALAT PERENCANAAN LABA PADA INDUSTRI MINUMAN KESEHATAN ( STUDI KASUS : JAHE INSTAN PUTRI KELURAHAN TIMUR INDAH KOTA BENGKULU )
}

\section{ANALYSIS OF BREAK EVENT POINT (BEP) AS A PROFIT PLANNING TOOL AT HEALTH DRINK INDUSTRY (CASE STUDY : INSTANT GINGER "PUTRI" TIMUR INDAH VILLAGE BENGKULU CITY)}

\author{
Romzi $^{1}$, Jusuf Wahyudi ${ }^{2}$, Yossie Yumiati ${ }^{3}$ \\ 1) Program Studi Agribisnis Fakultas Pertanian UNIVED \\ 2) Fakultas Pertanian UNIVED \\ 3) Program Studi Agribisnis Fakultas Pertanian UNIVED
}

\begin{abstract}
ABSTRAK
Analisis Break Event Point (BEP) atau titik impas merupakan teknik analisa untuk mempelajari hubungan antara biaya total, laba yang diharapkan dan volume penjualan. Melalui analisis break evenpoint perusahaan dapat membuat perencanaan laba sehingga diperoleh informas I tentang berapa jauh penjualan bias ditingkatkan atau diturunkan sehingga perusahaan tidak rugi. Tujuan penelitian ini adalah untuk mengetahui berapa produksi dan nilai penjualan jahe instan Putri agar mencapai BEP serta untuk mengetahui penggunaan analisis BEP dalam kaitannya sebagai perencanaan laba. Penelitian ini menggunakan metode studi kasus di industry minuman kesehatan jahe instan yang terletak di kelurahan Timur Indah kota Bengkulu. Penelitian dilakukan pada bulan Agustus 2012. Data yang digunakan adalah data primer dan data sekunder. Data primer diambil berdasarkan hasil wawancara dan observasi dengan panduan kuisioner sedangkan data sekunder diambil berdasarkan studi literature dan internet. Teknik analisa yang digunakan adalah analisa BEP kemudian dilanjutkan dengan perhitungan perencanaan laba dengan menggunakan analisis cost-volume-profit. Berdasarkan hasil penelitian diketahui bahwa industri minuman kesehatan jahe instan PutriTimur Indah Ujung kota Bengkulu harus memproduksi jahe instan sebesar $1.887,37 \mathrm{~kg}$ pertahun untuk mencapai BEP dengan nilai penjualan sebesar Rp. 94.368.000,- per tahun. Hasil analisis BEP dalam kaitannya dengan perencanaan laba digunakan analisis Cost-Volume-Equation dimana industri minuman kesehatan jahe instan Putri Timur Indah Ujung kota Bengkulu dapat ditingkatan dari Rp. 31.631.333,33,- menjadi Rp. 40.000.000,- dengan cara meningkatkan volume penjualan dari $2.520 \mathrm{~kg}$ per tahun menjadi $2683,53 \mathrm{~kg}$. Berdasarkan perhitungan yang dilakukan usaha Rp.31.631.333,33,pertahun.Perencanaan laba dapat dilakukan dengan mempertimbangkan perhitungan margin of safety, dimana perusahaan ini hanya dapat menurunkan volume penjualan sebesar $29,78 \%$ saja agar tidak menderita rugi.
\end{abstract}

Kata Kunci : BEP, profit, marjin keamanan 


\section{ABSTRACT}

Break Event Point (BEP) Analysis or break-even analysis is a technique for studying the relationship of total cost, expected profit and sales volume. Through the break-even point analysis the company's can make a planning profit in order to obtain information about how much sales could be increased or decreased so the company does not lose. The purpose of this study is to investigate how the production and sales of instant ginger princess in order to achieve the BEP and to investigate the use of BEP analysis in relation to the profit planning. This study uses a case study in health instant ginger beverage industry, located in Kelurahan Timur Indah Kota Bengkulu. The study was conducted in August 2012 that used are primary data and secondary data. Primary data taken based on interviews and observations by questionnaire, while secondary data taken based on the study of literature and the internet. Analytical technique used is the analysis of BEP followed by calculation of profit planning using the analysis of cost-volume-profit. Based on the survey results revealed that the health drink industry of ginger instant of Putri in Kelurahan Timur Indah Kota Bengkulu should produce instant ginger at 1,887.37 $\mathrm{kg}$ per year to reach the BEP with a sales value of $R p$. 94,368,000, - per year. The results of the BEP analysis related to profit planning used CostVolume-analysis equation where this health drink industry can be increased from Rp. 31,631,333.33 to Rp. 40,000,000.- by increasing of the sales volume from 2,520 kg per year to $2,683.53 \mathrm{~kg}$. Based on calculations that the instant ginger of Putri is quite profitable with a value gain Rp. 31.631.333,33, - per year. Profit planning can be done by considering the profit margin of safety calculation, where the company was only able to decrease the volume of sales by $29.78 \%$ in order not to suffer any loss.

Keywords : BEP, profit, Margin of safety

\section{PENDAHULUAN}

Industri adalah suatu usaha atau kegiatan pengolahan bahan mentah atau barang setengah jadi menjadi barang jadi yang memiliki nilai tambah untuk mendapatkan keuntungan. Industri pengolahan merupakan salah satu sektor industri yang memiliki kontribusi yang cukup besar terhadap pendapatan nasional negara. Tujuan mendirikan usaha tidak lain adalah untuk memperoleh keuntungan yang dapat dipergunakan untuk kelangsungan hidup. Kemajuan dan perkembangan usaha akan membawa akibat bagi pembangunan itu sendiri baik positif maupun negatif. Pada kalangan pengusaha itu sendiri, perkembangan dan kemajuan dunia usaha telah membawa kearah persaingan yang semakin ketat, sedangkan usaha untuk mencapai laba tidak dapat dipisahkan dari masalah penjualan, peningkatan penjualan yang tinggi bukan selalu berarti mendapatkan laba yang lebih besar. Industri yang diprioritaskan untuk dikembangkan menurut Zulkipli Husin (1999) adalah industri kecil (agro industri) 
yang bersifat padat karya dengan orientasi utama untuk memenuhi pasaran ekspor disamping pasaran dalam negeri. Hal ini disebabkan sektor industri kecil memiliki peranan penting dalam menjawab tantangan-tantangan pembangunan yaitu perluasan lapangan kerja bagi angkatan kerja yang bertambah terus jumlahnya.

Industri minuman kesehatan Jahe Instan Putri salah satu usaha yang termasuk industri kecil adalah yang bergerak dalam bidang pengolahan hasil pertanian di Kota Bengkulu yag telah diproduksi sejak 2008. Tujuan perusahaan pada umumnya adalah memperoleh laba optimal sesuai dengan kemampuan perusahaan karena laba seringkali dijadikan ukuran untuk menilai sukses tidaknya manajemen dalam mengelola sebuah perusahaan. Di dalam merencanakan laba dipengaruhi oleh tiga faktor yaitu harga jual, biaya dan volume penjualan. Dan untuk melihat hubungan dari ketiga unsur tersebut maka diperlukan suatu teknik analisis yaitu analisis titik impas atau break event point (BEP).

\section{METODE PENELITIAN}

Penelitian ini dilaksanakan pada bulan bulan Agustus 2012 pada Industri Minuman Kesehatan Jahe Instan Putri, Kelurahan Sidomulyo, Kota Bengkulu, Provinsi Bengkulu. Penelitian ini menggunakan metode studi kasus, yakni mengumpulkan data-data Kuantitatif (angka-angka) yang berkaitan dengan penelitian.

Data yang dikumpulkan diperoleh dari data primer dan data sekunder. Data yang diambil bersumber dari data primer yaitu data yang diperoleh dari hasil wawancara dan observasi langsung kepada pihak industri jahe instan dengan panduan kuisioner yang dibuat terlebih dahulu. Sedangkan data sekunder yaitu data yang diperoleh dari dokumen-dokumen Industri Minuman Jahe Instan Putri seperti laporan keuangan perusahaan serta bahan-bahan lain yang berkaitan dengan penelitian ini.

\section{Operasional Variabel}

Operasional variable yag digunakan meliputi (1) Produksi, (2) Biaya produksi, (3) Harga, (4) Penerimaan, (5) Pendapatan, (6) Biaya tetap, dan (7) Biaya variable. Metode analisis data yang dilakukan berupa (1) Menentukan data biaya variabel, biaya tetap, jumlah produksi dan harga produksi, (2) Menghitung Keuntungan (3) Analisis BEP, (4) Perencanaan Laba, dan (5) Margin of safety.

Untuk mengetahui BEP usaha industri minuman kesehatan Jahe Instan Putri digunakan pendekatan keuntungan sebagai berikut : 


$$
\pi=\mathrm{TR}-\mathrm{TC}
$$

Keterangan :

$\Pi=$ Keuntungan usaha Jahe Instan Putri

$$
\text { (Rp) }
$$

$\mathrm{TR}=$ Total Revenue (Total Penerimaan) Jahe Instan Putri (Rp)

$\mathrm{TC}=$ Total Cost (Total Biaya) Jahe Instan Putri (Rp)

Dalam keadaan BEP, $\Pi=0$, maka penerimaan (TR) sama dengan biaya produksi total.

$$
\mathrm{TR}=\mathrm{TC}
$$

Penerimaan adalah nilai yang diterima dari produksi pengusaha atau perkalian antara produksi dengan harga jual. Secara matematis dirumuskan sebagai berikut :

$$
\mathrm{TR}=\mathrm{P} \times \mathrm{Pq}
$$

Pada saat harga $(\mathrm{Pq})$ tetap, produksi $(\mathrm{P})$ yang harus dicapai agar BEP adalah :

$$
\mathrm{P}=\mathrm{TC} / \mathrm{Pq}
$$

Pada produksi (P) tetap, penerimaan pengusaha pada saat BEP adalah :

$$
\mathrm{TR}=\mathrm{P} \times \mathrm{Pq}
$$

BEP Produksi adalah $\mathrm{P}=\mathrm{TC} / \mathrm{Pq}$

BEP Penjualan adalah $\mathrm{TR}=\mathrm{P} \times \mathrm{Pq}$

Sedangkan penggunaan analisis BEP dalam kaitannya dengan perencanaan laba digunakan analisis Cost-Volume-Profit Equation dengan menggunakan persamaan berikut ini (Mulyadi, 1990) :

$$
\mathrm{px}=\mathrm{a}+\mathrm{bx}+\mathrm{c}
$$

Dimana:

$$
\mathrm{px}=\text { Impas dalam satuan }
$$
penjualan (BEP Rp)

$$
\begin{array}{ll}
\mathrm{a} & =\text { biaya tetap }(\mathrm{FC}) \\
\mathrm{bx} & =\text { biaya variabel }(\mathrm{VC}) \\
\mathrm{c} & =\text { Laba yang diinginkan }
\end{array}
$$

Perhitungan Margin of safety dilakukan sebagai informasi pada pihak manajemen mengenai berapa basarnya perubahan volume penjualan yang masih dapat diterima agar industri tidak menderita kerugian.

Besarnya margin of safety dapat dihitung dengan menggunakan rumus sebagai berikut (Bambang Riyanto, 1995) :

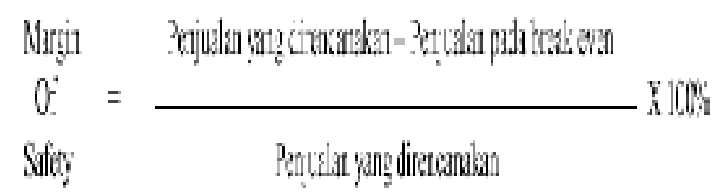

\section{HASIL DAN PEMBAHASAN}

\section{Volume Produksi, Harga dan Omzet}

Usaha ini didirikan pada bulan Agustus 2008 dan seiring berjalannya waktu usaha ini semakin menampakan hasil dengan semakin meningkatnya produksi dan volume penjualan setiap tahunnya. 
Tabel 1. Volume Produksi, Harga dan Omzet penjualan Jahe Instan Putri Tahun 2008 - 2011

\begin{tabular}{ccccc}
\hline NO & Tahun & Volume Produksi $(\mathrm{Kg})$ & Harga Penjualan $(\mathrm{Kg})$ & Omzet Penjualan $(\mathrm{Rp})$ \\
\hline 1 & 2008 & 900 & 35.000 & 31.500 .000 \\
2 & 2009 & 2.400 & 35.000 & 84.000 .000 \\
3 & 2010 & 1.920 & 40.000 & 76.800 .000 \\
4 & 2011 & 1.680 & 50.000 & 84.000 .000
\end{tabular}

Sumber : Data primer

Tabel 1. di atas menjelaskan bahwa omzet penjualan terus mengalami peningkatan dari tahun 2008 sampai dengan 2009 dan menurun di tahun 2010 dan 2011. Namun jika dilihat dari harga jual produksi perkilogramnya mengalami peningkatan. Dengan demikian prospek usaha minuman kesehatan Jahe cukup menguntungkan karena harga jualnya terus meningkat.

\section{Penggolongan Biaya-biaya Produksi}

1. Biaya variabel (VC)

Biaya variabel terdiri dari biaya bahan baku, biaya bahan bakar, biaya kemasan, upah gaji/karyawan dan biaya variabel lain seperti listrik, telpon, air, transportasi dan adminitrasi umum (lihat lampiran 1).

Sehingga total biaya variabel adalah sebesar : Rp. 87.792.000,-

2. Biaya Tetap (FC)

Biaya tetap terdiri dari biaya penyusutan alat (lihat lampiran 1) dengan total biaya tetap sebesar : Rp.

\section{$6.576 .666,67$}

3. Total biaya adalah (TC):

$\mathrm{VC}+\mathrm{FC}=\mathrm{TC}$, sehingga :

$87.792 .000+6.576 .666,67=$
$94.368 .666,67$

\section{Analisis Break Even Point}

Untuk mengetahui BEP usaha industri minuman kesehatan jahe Instan Putri digunakan pendekatan keuntungan sebagai berikut :

$$
\pi=\mathrm{TR}-\mathrm{TC}
$$

Pada saat keuntungan $=0$, maka penerimaan usaha minuman kesehatan Jahe Instan Putri sama dengan biaya yang dikeluarkan. Penerimaan usaha minuman Kesehatan Jahe Instan Putri yang dihasilkan dikalikan dengan harga yang diterima. Produksi yang dihasilkan adalah $2.520 \mathrm{~kg}$ dan harga yang diterima adalah Rp. 50.000,- per kilogram, maka penerimaan pengusaha adalah 
126.000.000,- (TR).

Biaya yang dikeluarkan adalah Rp.94.368.666,67 sehingga diperoleh keuntungan yaitu sebesar :

$$
\pi=\mathrm{TR}-\mathrm{TC}
$$

$126.000 .000-94.368 .666,67=$

\section{$31.631 .333,33$}

Untuk mengetahui produksi yang harus dijual agar mencapai BEP adalah :

$$
\begin{aligned}
\mathrm{BEP} \text { Unit } & =\mathrm{TC} / \mathrm{Pq} \\
& =94.368 .666,67 / 50.000 \\
& =1.887,37 \mathrm{~kg}
\end{aligned}
$$

Dengan BEP produksi sebesar 1.888,54 kg berarti produksi minimum yang harus

\section{Peniualan dan Biaxa}

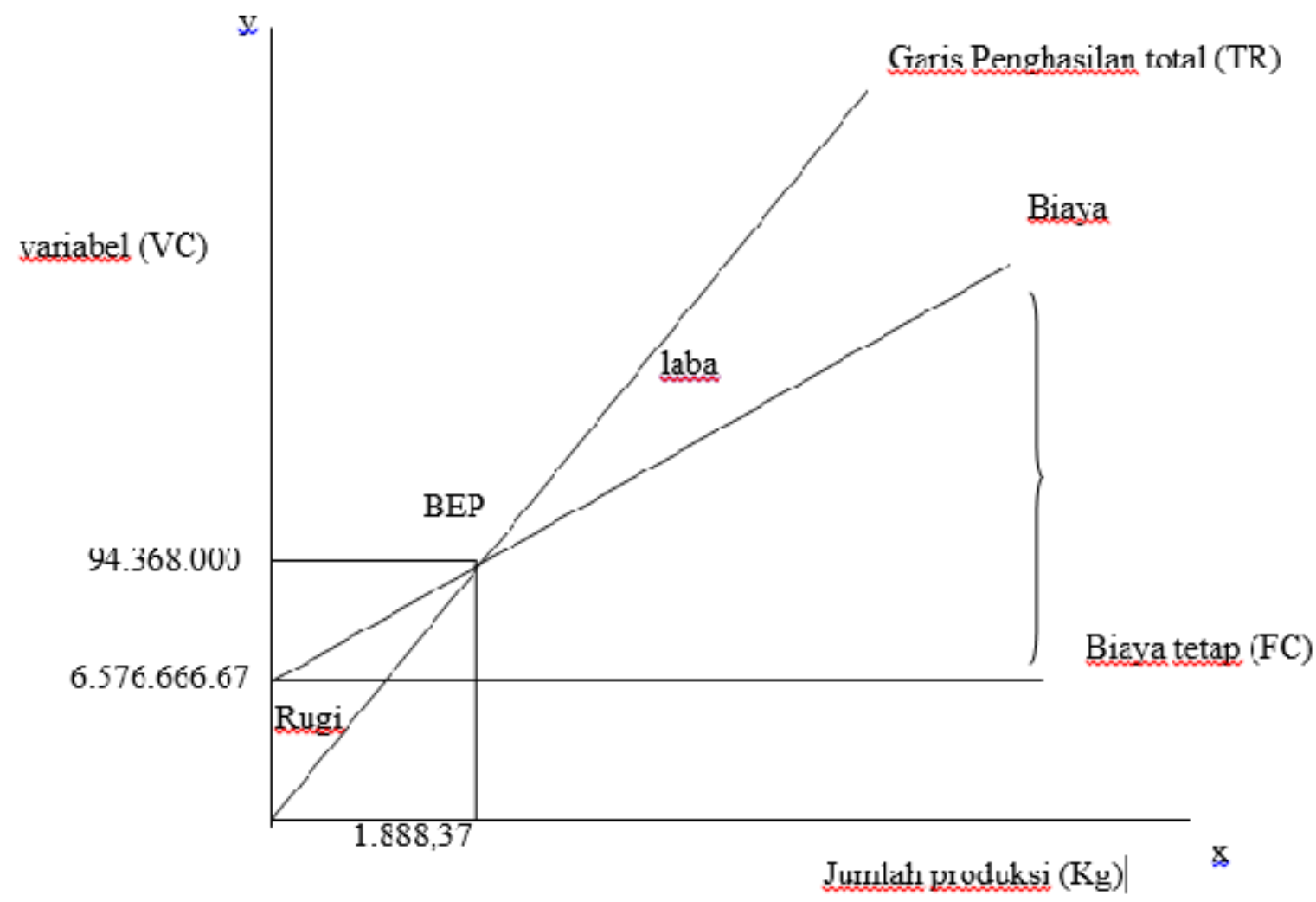

Gambar 1. Grafik Break Event Point 
Dalam grafik break even point menggambarkan hubungan antara total biaya (TC), volume penjualan dan tingkat penghasilan (TR), biaya tetap (FC) dan biaya variabel (VC). Besarnya volume produksi dalam unit terlihat pada sumbu horizontal (sumbu $\mathrm{x}$ ) dan besarnya biaya serta penghasilan penjualan terletak pada sumbu vertikal (sumbu Y), break even point terletak pada titik terjadinya persilangan antara garis penghasilan penjualan dan garis total biaya.

Gambar 1. di atas menunjukkan bahwa industri minuman jahe instan putri dapat mencapai titik break even poin pada penjualan sebanyak $1.888,37 \mathrm{~kg}$ atau volume penjualan sebesar Rp. 94.368.000. Pada posisi tersebut perusahaan tidak mengalami kerugian dan juga tidak memperoleh laba atau sama dengan nol.

\section{Perencanaan Laba}

Penggunaan analisis BEP dalam kaitannya dengan perencanaan laba digunakan analisis Cost-Volume-Profit Equation dengan menggunakan persamaan berikut ini (Mulyadi, 1990) :

$$
p x=a+b x+c
$$

Dimana:

px = Impas dalam satuan penjualan (BEP Rp)

$$
\begin{array}{ll}
\mathrm{a} & =\text { biaya tetap }(\mathrm{FC}) \\
\mathrm{bx} & =\text { biaya variabel }(\mathrm{VC})
\end{array}
$$

$$
\text { c = Laba yang diinginkan }
$$

Berdasarkan perhitungan sebelumnya diperoleh laba sebesar: $31.631 .333,33$. Jika perusahaan ingin meningkatkan laba menjadi 40.000.000 di tahun 2012 maka volume penjualan produk harus ditingkatkan, karena volume penjualan berpengaruh terhadap volume produksi. Dengan demikian dapat dihitung sebagai berikut :

$\begin{array}{cl}\mathrm{px} & =\mathrm{a}+\mathrm{bx}+\mathrm{c} \\ 50.000 \mathrm{x} & =6.576 .666,67+ \\ 87.792 .000+ & 40.000 .000 \mathrm{x}=\end{array}$
$134.368666,67 / 50.000 x=2687,53$ unit $/ \mathrm{kg}$. Dengan demikian jika usaha industri minuman kesehatan Jahe Instan Putri ingin meningkatkan labanya dari $\mathrm{Rp}$. 31.631333,33,- menjadi Rp. 40.000.000,pertahun maka volume penjualan produknya harus ditingkatkan dari 2.520 $\mathrm{kg}$ menjadi $2687 \mathrm{~kg}$ pertahun dengan ketentuan data yang digunakan adalah data terakhir.

\section{Marjin Keamanan (Margin of safety)}

Marjin keamanan adalah selisih antara rencana penjualan (dalam unit atau satuan uang) dengan impas (dalam unit atau satuan uang) penjualan. Marjin keamanan dilakukan agar dapat diketahui informasi mengenai seberapa jauh realisasi penjualan dapat turun dari rencana penjualannya agar 
perusahaan tidak menderita rugi. Penurunan realisasi penjualan dari rencana penjualan maksimum harus sebesar margin keamanan agar perusahaan tidak rugi.

$$
\begin{aligned}
& \begin{array}{ccc}
\text { Margin Of } & 2687,53- & \mathrm{X} \\
\text { Safety }= & 1887,37 & 100 \% \\
& 2687,53 &
\end{array} \\
& =29,78 \%
\end{aligned}
$$

Dari hasil perhitungan margin of safety di atas dapat dijelaskan bahwa agar industri minuman kesehatan jahe instan putri tidak mengalami kerugian maka dengan rencana penjualan sebesar $2687,53 \mathrm{~kg}$ pertahun maka volume penjualan hanya boleh turun sebesar 29,78 persen dari rencana penjualan yang direncanakan kalau tidak demikian maka perusahan akan mengalami kerugian.

\section{SIMPULAN}

Berdasarkan hasil penelitian dan pembahasan maka dapat disimpulkan sebagai berikut :

1. Industri minuman kesehatan jahe instan Putri harus memproduksi jahe instan sebesar $1.887,37 \mathrm{~kg}$ pertahun untuk mencapai BEP.

2. Nilai penjualan minuman kesehatan jahe instan Putri yang harus diterima sebesar Rp. 94.368.000,- pertahun agar mencapai BEP.

3. Analisis BEP dalam kaitannya dengan perencanaan laba menggunakan analisis Cost-Volume-Equation dimana industri minuman kesehatan jahe instan Putri dapat ditingkatkan dari Rp. 31.631.333,33,-- menjadi Rp. 40.000.000,-dengan cara meningkatkan volume penjualandari $2.520 \mathrm{~kg}$ pertahun menjadi $2.683,53$ $\mathrm{kg}$ pertahun dengan ketentuan data yang digunakan adalah data terakhir.

Berdasarkan perhitungan yang dilakukan usaha minuman kesehatan jahe instan Putri cukup menguntungkan dengan nilai keuntungan sebesar Rp.31.631.333,33,-- pertahun.

\section{DAFTAR PUSTAKA}

Ahmad, Kamaruddim. 2005. Akuntansi Manajemen. Jakarta. Raja Grafindo Persada.

Dewi Ariyanti, Rikeu. (2005). Kememadaian Analisis Break Event Sebagai Alat Bantu Bagi Manajemen Dalam Perencanaan Laba Perusahaan. Skripsi Universitas Widyatama Bandung: diterbitkan.

Harmono, Dr. (2009). Manajemen Keuangan Edisi 1. Jakarta: Bumi Aksara.

Kamelia, Lisia. (2006). Pengaruh Harga Jual Dan Biaya Promosi Terhadap Volume Penjualan Teh pada SBUTK PT.Perkebunan Nusantara. Skripsi Universitas Widyatama Bandung: diterbitkan

Marhaeni, Agustina Pradita. (2011). Analisis Break Even Point Sebagai Alat Perencanaan Laba 
Pada Industri Kecil Tegel di Kecamatan Pedurungan. Skripsi Universitas Diponegoro Semarang.

Mardiasmo. Akuntansi Biaya. 1993 Gunadama. Jakarta,

Mulyadi. (2001). Akuntansi Manajemen Edisi 3. Jakarta: Salemba

Nazir, Moh. (2005). Metode Penelitian Edisi 6. Bogor: Ghalia Indonesia.

Riyanto, Bambang. (2008). Dasar-Dasar Pembelanjaan Perusahaan. Yogyakarta: BPFE. Yogyakarta.

Zulkipli Husin.1999. Alternatif Pemberdayaan Ekonomi Kerakyatan : Upaya Kemandirian Kelompok Masyarakat Miskin dan Usaha Kecil. Makalah pada seminar sehari 1 maret 1999. Bengkulu 